\title{
The Stigmatisation of Obesity by University Students Who Will be the Future Counsellors, Educators, and Psychologists*
}

\author{
Sultan Okumuşoğlu \\ Europian University of Lefke, Lefke, Türkiye
}

\begin{abstract}
To investigate the attitudes of prospective councellors, psychologists, and educators, Obesity Prejudice Scale was used. Participants are ninety university students, thirty from each mentioned department. Founded mean score $82,422(S D=1,091)$ is very close to 85 which indicates prejudical attitudes. Even for the group of participants who informed they have no prejudical bias toward people with obesity, total mean scores was not below 68 which means unstigmatising attitudes. Participants who attribute personal responsibility for obesity condition are more biased toward people with obesity than participants who does not. Mean scores above three (on five point likert) at item level accepted as indicators of the participants' biased attitudes. According to mentioned findings, people with obesity conceptualised as "unhealthy" people, who "doesn't like to move", "has restricted ability to move", "moves slowly", "quickly get tired", "vulnerable to ilnesses", "smelling sweat", "unattractive", "unhappy", "unesthetic", "lazy people", who doesn't have "self confidence" or "will power", "unfavoruable for sentimental relationships", "seem older than they really are". Stigmatising attitudes towards people with obesity held by authority figures at school settings dangerously depletes the potential for early detection and prevention for obesity and eating disorders. Therefore findings implies a need to plan educational intervention programs for prospective counsellors, educators and psychologists to shape more positive, more indiscriminative attitudes.
\end{abstract}

Keywords: obesity stigma, attitudes, stereotypes, people with obesity, stigmatisation

\section{Introduction}

The word "Stigma" is such a concept which can be explained with "negative labeling", "stereotyping" and many other concepts which implies negativity. It is a study area which has became topic of interest for many researchers (Jorm, Christensen, \& Griffiths, 2005; Link \& Phelan, 2001; Corrigan, 2005). The word "Stigma" accomodates ignorance, prejudice, negative attitudes and discrimination too (Thornicroft, Rose, Kassam, \& Sartorius, 2007). Stigma includes stereotypes which relates the target person with a set of negative characteristics and these stereotypes are resistant to change (Jacoby, Snape, \& Baker, 2005). People can be stigmatised because of many different reasons and one of these reasons is obesity. People who has Body Mass Index greater than $30(\mathrm{BMI} \geq 30)$ are accepted as having obesity (Ogden, 2007; WHO, 2013). Obesity is accepted as a global epidemic; a pandemic (Ogden, 2014; WHO, 1997). Therefore, there are lots of studies

\footnotetext{
${ }^{*}$ This study have been presented at International "7th World Conference on Psychology, Counseling and Guidance (WCPCG-2016)", April, 28-30, 2016, Kuşadası, İzmir, Türkiye.

Sultan Okumuşoğlu, Ph.D. (Clinical Psychologist), Department of Psychology, Europian University of Lefke.
} 
about stigmatisation of individuals with obesity which reflects existence of weight bias (Harriger, Calogero, Witherington, \& Smith, 2010; Link, Yang, Phelan, \& Collins, 2004; O’Brien et al., 2008; Sayce, 1998). According to Carr and Friedman (2005), the discrimination that people with obesity encounter is one of the worst a person can encounter in social context.

Stigmatisation hosts many disadvantages for people with obesity and leads to negative consequences in multiple areas of lives of people with obesity including health (Major \& O'Brien, 2005). Stigmatisation and related negative consequences may arise in many different settings and in many different forms. Sikorski et al. (2013), emphasized the negative attitudes of health workers toward people with obesity and they explained how harmfull this could be through preventing help seeking behavior. Even perceived discrimination effects people's lives and treatment results (Sikorski et al., 2011). Stigmatising attitudes, intolerant and negative attitudes toward people who are fighting with obesity have a link with low self-esteem (Puhl \& Brownell, 2006), social isolation, depression and future eating disorders (Tang-Peronard \& Heitmann, 2008) for stigmatised one. Thereby stigmatisation deteriorates physical and psychological well being of the targeted person.

When students with obesity or overweight encounter with negative, stigmatising attitudes, their psychological well being and participation to school activities being affected unfavourable (Bauer, Yang, \& Austin, 2004). When the target of the negative attitudes and discrimination is young students, it is obvious that all mentioned negative effects of stigmatisation will be maximized.

The potential of school setting for early detection and prevention efforts for obesity or eating disorders is huge. School setting also has potential for prevention of development of negative attitudes toward the "other" including weight based discrimination. Under the light of related literature, it is obvious that negative attitudes held by authority figures who work with students at school settings has crucial importance. Thereby the aim of this study was investigation of stigmatised attitudes toward people with obesity at a group of prospective councellors, psychologists, and educators. Therefore, in this study weight based prejudical attitudes of a group of future councellors, psychologists, and educators have been investigated.

\section{Method}

\section{Participants}

Participants are ninety university students from fourth grades of various departments of various universities. Fourth grades have choosen since they are close to perform their job. The students are from Psychology Departments, Psychological Counselling and Guidance Departments and from other departments of Education Faculties which raise teachers for intermediate level schools. Thirty university students from each of the mentioned departments were reached according to convenience principle till equal groups are handled. There is 39 women and 51 men. The percentages of women and men in groups are approximately matched (see Table 1). Age range is between 18 to $27(M=20.366, S D=1.725)$. Participants' Body Mass Index (BMI) which was calculated through division of weight by the square of height is between $15.62 \mathrm{~kg} / \mathrm{m}^{2}$ to $32.49 \mathrm{~kg} / \mathrm{m}^{2}$ ( $M=22.435, S D=2.954) .75 .55 \%$ of the participants' BMI is in "normal" range (18 $\geq$ normal BMI $\leq 24.9)$. In terms of BMI there is no statistically meaningfull difference among groups. Participants are from various parts of Turkey (13 from Marmara Region, 18 from Aegian Region, 27 from Mediterranean Region and 32 from Eastern Anatolia region). 
Table 1

Crosstabulation for Sex among Groups

\begin{tabular}{llllllllll}
\hline \multirow{2}{*}{ Groups } & & \multicolumn{3}{c}{ Psychologists } & \multicolumn{1}{c}{ Counsellors } & \multicolumn{2}{c}{ Teachers } & \multicolumn{2}{c}{ Total } \\
\cline { 2 - 10 } & & $N$ & $\%$ & $N$ & $\%$ & $N$ & $\%$ & $N$ & $\%$ \\
\hline \multirow{2}{*}{ Sex } & Women & 13 & 43.3 & 14 & 46.7 & 12 & 40 & 39 & 43.3 \\
& Men & 17 & 56.7 & 16 & 53.3 & 18 & 60 & 51 & 56.7 \\
\hline
\end{tabular}

\section{Tools}

The Obesity Prejudice Scale and Demographic Information Form were performed.

\section{Obesity Prejudice Scale}

For assesment of discriminative, prejudical attitudes of participants, the Obesity Prejudice Scale which was developed by Ercan, Akçil Ok, Kızıltan, and Altun (2015) was used. It is a 27 item, 5 point likert type scale. Possible scores which participants can get from this scale are between 27 to 135. Higher scores mean higher prejudice. According to Ercan et al. (2015) Obesity Prejudice Scale scores which are $\leq 68.00$ indicate unpredjudiced attitudes. Scores between 68.01-84.99 reveal inclination to prejudical attitudes and scores $\geq 85$ means having prejudical attitudes.

\section{Demographic Information Form}

By this form which was prepared by investigator participants' demographics like sex, age, department, and home city were recorded. Participants' attributions about personal responsibility of individuals with obesity and participants self perceptions about their own weight were also asked. Also participants self informed weight and height were handled and BMI was calculated through this data.

\section{Procedure}

Ethical rules followed, each participant was volunteer. After informed consent and anonimity guaranty were provided by the investigator, scales were administered to the participants who volunteered to enrol.

\section{Statistical Analysis}

Data analysis was performed by Statistical Package for Social sciences (SPSS-16). Statistical signifance level was choosen as 0.05 .

Since the main aim of this study is handling data about prejudice level of prospective professionals who will work at school settings, descriptive statistics of total Obesity Prejudice Scale scores were performed to handle total stigmatisation level of participants and to get item level biased conceptualisations of participants. Also descriptive statistics carried out to see sample demographics.

Also, in order to investigate attitude differences among groups, one way variance analysis (ANOVA) were performed. Participants' total Obesity Prejudice Scale scores were used as dependent variables and groups as independent variables. Groups were formed according to departments of participants. Beside this, groups were formed through personal responsibility attribution for obesity condition, self reported prejudical attitudes, sex, self perception about their own weight, and home city.

\section{Results}

\section{Descriptive Statistics of Total Obesity Prejudice Scale Scores}

According to descriptive statistical analysis, the range of participants Obesity Prejudice Scale scores is 
between 58 to $122(M=82.422, S D=1.091)$. Mean score 82,422 reveal inclination to prejudical attitudes.

According to Ercan et al. (2015), Obesity Prejudice Scale scores which are $\leq 68.00$ points out unpredjudiced attitudes. Scores between 68.01-84.99 reveal inclination to prejudical attitudes and scores $\geq 85$ means prejudical attitudes.

According to means for each item which are above three on the five point likert scale at least most of the participants attitudes for certain items are biased like this: Participants generally have a tendency to think that people with obesity "don't like to move" and "have restricted ability to move". They think people with obesity are "unhealthy" people, who "move slowly", "quickly get tired", "vulnerable to ilnesses", "smell sweat", "unattractive", "unhappy", "unesthetic", "lazy" people. They think people with obesity "don't have self confidence" or "will power", "unfavourable for sentimental relationships" and "seem older than they really are" (see Table 2).

Table 2

Descriptive Statistics for Obesity Prejudice Scale Items by Ascending Means

\begin{tabular}{|c|c|c|c|}
\hline Items & People with obesity... & Mean for item & Std. Deviation \\
\hline ObPrejudice 12 & Restricted Ability to move & 3.8667 & 1.13375 \\
\hline ObPrejudice 15 & Unhealthy & 3.7778 & 1.11957 \\
\hline ObPrejudice 23 & Slow & 3.7667 & 1.17129 \\
\hline ObPrejudice 21 & Get tired easily & 3.7333 & 1.26135 \\
\hline ObPrejudice 6 & Vulnearble to ilnesses & 3.7000 & 1.08566 \\
\hline ObPrejudice 11 & Unattractive & 3.5667 & 1.01727 \\
\hline ObPrejudice 16 & Do not like to move & 3.4000 & 1.32224 \\
\hline ObPrejudice 7 & Unhappy & 3.2444 & 0.96350 \\
\hline ObPrejudice 3 & Unesthetic & 3.2222 & 1.13946 \\
\hline ObPrejudice 24 & Lazy & 3.2111 & 1.24967 \\
\hline ObPrejudice 17 & Do not have self confidence & 3.2000 & 0.99662 \\
\hline ObPrejudice 13 & Smell sweat & 3.1667 & 1.11426 \\
\hline ObPrejudice 5 & Do not have will power & 3.0889 & 1.22378 \\
\hline ObPrejudice 26 & Unfavourable for sentimental relationships & 3.0778 & 1.09368 \\
\hline ObPrejudice 19 & Seem older then they are & 3.0667 & 1.12978 \\
\hline ObPrejudice 18 & Have low quality of life & 2.9889 & 1.13667 \\
\hline ObPrejudice 20 & Strong at social relations & 2.8000 & 1.01892 \\
\hline ObPrejudice 8 & Do not like to eat in public & 2.7778 & 1.23414 \\
\hline ObPrejudice 22 & Good listeners & 2.7667 & 0.96045 \\
\hline ObPrejudice 25 & Cook well & 2.7333 & 1.10971 \\
\hline ObPrejudice 10 & Hospitable & 2.6778 & 0.94605 \\
\hline ObPrejudice 2 & Have beautiful face & 2.6667 & 1.01671 \\
\hline ObPrejudice 4 & Good humored & 2.5889 & 1.02655 \\
\hline ObPrejudice 9 & Coward & 2.4667 & 0.99662 \\
\hline ObPrejudice 27 & Outgoing & 2.4556 & 0.97337 \\
\hline ObPrejudice 14 & Sympathetic & 2.4222 & 1.00535 \\
\hline ObPrejudice 1 & Selfish & 1.9889 & 0.96564 \\
\hline
\end{tabular}

Note. Obesity Prejudice Scale items were rated on a five point likert.

\section{Analysis of Variance (ANOVA)}

(1) One way ANOVA between groups based on personal responsibility attribution to people with obesity for their condition and total Obesity Prejudice Scale scores 
Participants grouped according to informed attributions about personal responsibility of individuals with obesity for their condition. The number of participants who informed that they believe people with obesity are responsible for their condition is 57 and 33 participants informed they do not think people with obesity have personal responsibility for their condition. Variance analysis between these two groups revealed a statistically significant difference $\left(F(1,88)=94.553, p<0.05, \mu^{2}=0.518\right)$. According to this result, participants who attribute personal responsibility $(M=88.368, S D=8.557)$ are more biased toward people with obesity than participants who does not $(M=72.151, S D=5.629)$.

(2) One way ANOVA between groups based on participants' departments and total Obesity Prejudice Scale scores

Analysis revealed no statistically significant differences among departments in terms of total Obesity Prejudice Scale scores $(F(2,87)=0.266, p>0.05)$.

(3) One way ANOVA between groups based on self reported prejudical attitudes and total Obesity Prejudice Scale scores

Participants were asked to inform either they have prejudical attitudes towards people with obesity or not. The percentage of participants informed they have no prejudical attitude toward people with obesity is $88.88 \%$ $(M=81.687, S D=10.253)$ and $11.11 \%$ informed they have prejudical attitude $(M=88.300, S D=14.598)$. Depending on existence and non-existence of self reported prejudical attitudes two groups were formed. One Way ANOVA between these two groups and total Obesity Prejudice Scale scores revealed no statistically significant differences among mentioned groups $(F(1,88)=3.346, p>0.05)$.

(4) One way ANOVA between total Obesity Prejudice Scale scores and Sex

Analysis which performed to see differences among males and females in terms of Obesity Prejudice Scale scores depending on sex showed no statistically significant differences $(F(1,88)=2.44, p>0.05)$.

(5) One way ANOVA between groups based on self perception about own weight and total Obesity Prejudice Scale scores

Participants were asked to inform how they percept their own weight by choosing from given words as "thin", "medium/normal" and "overweight". Variance analysis among these groups which determined according to self percepted weight revealed no statistically significant differences among groups in terms of total Obesity Prejudice Scale scores $(F(2,87)=2.014, p>0.05)$. Since informed weight is "medium/normal" for 71 of the participants over 90, group sizes are uneven.

(6) One way ANOVA between participants departments and BMI scores

Participants weight and height were asked and Body Mass Index (BMI) was calculated through this data. Analysis revealed no statistically meaninfull differrences among department groups in terms of BMI $(F(1,87)$ $=0.53, p>0.05$ ) which indicates groups are matching in terms of BMI.

\section{Discussion and Conclusion}

The main aim of this study was investigation of stigmatising attitudes toward obesity among prospective professionals who will work at school settings. Founded general mean score 82,422 reveal a tendency to prejudical attitudes. This score is close but higher than the mean $(M=76.394)$ which was founded by Ercan et al. (2015). When it is thought that having scores which are equal to or greater than 85 indicates prejudical attitudes, it became obvious that this founded "moderate" tendency to prejudical attitudes is very strong. 
Results of this study point out a general tendency of participants to have biased attitudes toward people with obesity to conceptualize them as individuals who "does not like to move" and "have restricted ability to move". Participants tend to think people with obesity as "unhealthy" people, who "move slowly", "quickly get tired", "vulnerable to ilnesses", "smelling sweat", "unattractive", "unhappy", "unesthetic", and "lazy". They tend to think people with obesity "do not have self confidence" or "will power", "do not prefferred for sentimental relationships" and "seem older than they really are". Findings are paralel with other studies which pointed out negative attitudes toward people with obesity (Chambliss, Finley, \& Blair, 2004; Harris, Sandoval, \& Cortese, 1998; Sikorski et al., 2011, 2013).

Analysis revealed that even participants who informed they have no prejudical bias toward people with obesity does not have mean scores below $68(M=81.687, S D=10.253)$ which means having non-prejudical attitudes. It means people have no insight about their biased attitudes toward people with obesity as mentioned in Miller et al.'s study (2013).

The participants who attribute personal responsibility for obesity condition $(M=88.368, S D=8.557)$ are founded more biased toward people with obesity than participants who does not $(M=72.151, S D=5.629)$. It is paralel with the literature which relates stigmatising attitudes and rejection with personal responsibility attribution (Crandall et al., 2001; Weiner, Perry, \& Magnusson, 1988).

School setting has potential to increase the risk factors which creates vulnerability for any kind of psychological disturbance like eating disorders and obesity. School setting is also important in terms of early detection and prevention efforts for obesity and for eating disorders, and for any kind of psychological disturbance. Even perceived discrimination effects people's lives (Sikorski et al., 2011). Therefore, it is obvious that discriminative prejudical attitudes by authority figures will effect all these areas negatively, will make things worst. These facts increase the importance of negative attitudes held by authority figures at school settings.

Beside possible effects to self esteem and psychological well being of students with obesity, attitudes of councellors, psychologists, and teachers who work with students have potential to shape students' attitudes towards obesity, therefore findings of present study seems alarming.

As pointed out (Puhl, Chelsea, \& Heuer, 2010), the stigmatisation of obesity creates barriers for promotion of effective intervention efforts beside having undesired consequences in terms of health. Because of all possible negative consequences, findings of this study implies a serious need to shape indiscriminative attitudes to promote acceptance about weight diversity. The findings of present study implies a need for comprehensive educational interventions which can challenge existing stereotypes for university students who will be the future counsellors, educators and psychologists.

Results also points out a need for future research about the factors effecting weight stigma in order to be able to plan future educational intervention programs that adressing to these aspects. Because of sample size there might be limitations in terms of generalisability, therefore results of present study can be accepted as a pilot study for guidelines to design future studies with bigger sample sizes to study prevelance of weight stigma among prospective professionals of school settings.

\section{References}

Bauer, K. W., Yang, Y. W., \& Austin, S. B. (2004). "How can we stay healthy when you're throwing all of this in front of us?" Findings from focus groups and interviews in middle schools on environmental influences on nutrition and physical activity. Health Education \& Behavior, 31, 34-46. 
Carr, D., \& Friedman, M. A. (2005). Is obesity stigmatizing? Body weight, perceived discrimination, and psychological well-being in the United States. Journal of Health and Social Behaviors, 46, 244-259.

Chambliss, H. O., Finley, C. E., \& Blair, S. N., (2004). Attitudes toward obese individuals among exercise science students. Medicine and Science in Sports and Exercise, 36(3), 468-474.

Corrigan, P. (2005). On the stigma of mental illness. Washington, D.C.: American Psychological Association.

Crandall, C. S., D’Anello, S., Sakalli, N., Lazarus, E., Nejtardt, G. W., \& Feather, N. T. (2001). An attribution-value model of prejudice: Anti-fat attitudes in six nations. Journal of Personality and Social Psychology, 27, 30-37.

Ercan, A., Akçil Ok, M., Kızıltan, G., \& Altun, S. (2015). Sağlık bilimleri öğrencileri için obezite önyargı ölçeğinin geliştirilmesi: GAMS 27-obezite önyargı ölçeği. DBHAD Uluslararası Hakemli Beslenme Araştırmaları Dergisi, 3(2), 29-43. Doi:10.173 62/ DBHAD.2015310322.

Harriger, J. A., Calogero, R. M., Witherington, D. C., \& Smith, J. E. (2010). Body size stereotyping and internalization of the thin ideal in preschool girls. Sex Roles, 63, 609-620. doi: 10.1007/sI1199-010-9868-1.

Harris, M. B., Sandoval, W. M., \& Cortese, S. (1998). Introductory nutrition students' attitudes towards obesity: Ethnic and gender differences. International Journal of Consumer Studies, 22(4), 231-240.

Jacoby, A., Snape, D., \& Baker, G. A. (2005). Epilepsy and social identity: The stigma of a chronic neurological disorder. Lancet Neurology, 4(3),171-178, doi:10.1016/s1474- 4422(05)700 20-x, PMID 15721827.

Jorm, A. F., Christensen, H., \& Griffiths, K. M. (2005). The impact of beyondblue: The national depression initiative on the Australian public's recognition of depression and beliefs about treatments. Australian and New Zealand Journal of Psychiatry, 39, 248-254.

Link, B. G., \& Phelan, J. C. (2001). Conceptualizing stigma. Annual Review of Sociology, 27, 363-385.

Link, B. G., Yang, L. H., Phelan, J. C., \& Collins, P. Y. (2004). Measuring mental illness stigma. Schizophrenia Bulletin, 30 , 511-541.

Major, B., \& O’Brien, L. T. (2005). The social psychology of stigma. Annual Review of Psychology, 56, 393-421.

Miller, D. P., Spangler, J. G., Vitolins, M. Z., Davis, S. W., Ip, E. H., Marion, G. S., \& Crandall, S. J. (2013). Are medical students aware of their anti-obesity bias? Academic Medicine, 88(7), 978-982.

O'Brien, K. S., Latner, J. D., Halberstadt, J., Hunter, J. A., Anderson, J., \& Caputi, P. (2008). Do antifat attitudes predict antifat behaviours? Obesity, 16(2), 87-92.

Ogden, J. (2007). Obesity and coronary hearth disease. In Health psychology (4th ed.) (pp. 333-363). NewYork: McGraw Hill.

Ogden, C. L. (2014). Prevalence of obesity among adults: United States, 2011-2012. Medical Benefits, 30(25), 9-17.

Puhl, R. M., \& Brownell, K. D. (2006). Confronting and coping with weight stigma: An investigation of overweight and obese adults. Obesity, 14, 1802-1815.

Puhl, R. M., Chelsea, A., \& Heuer, M. P. H. (2010). Obesity Stigma: Important considerations for public health. American Journal of Public Health, 100, 1019-1028.

Sayce, L. (1998). Stigma, discrimination and social exclusion: What's in a word. Journal of Mental Health, 7, 331-343.

Sikorski, C., Luppa, M., Glaesmer, H., Brähler, E., König, H. H., \& Riedel-Heller, S. G. (2013). Attitudes of health care professionals towards female obese patients. Obesity Facts, 6(6), 512-522.

Sikorski, C., Luppa, M., Kaiser, M., Glaesmer, H., Schomerus, G., König, H. H., \& Riedel- Heller, S. G. (2011). The stigma of obesity in the general public and its implications for public health. A Systematic Review, 23(11), 661. doi: 10.1186/14712458-11-661.

Tang-Peronard, J. L., \& Heitmann, B. L. (2008). Complications of obesity: Stigmatization of obese children and adolescents, the importance of gender. Obesity Reviews, 9, 522-534.

Thornicroft, G., Rose, D., Kassam, A., \& Sartorius, N. (2007). Stigma: Ignorance, prejudice or discrimination? British Journal of Psychiatry, 190, 192-193.

Weiner, B., Perry, R. P., \& Magnusson, J. (1988). An attributional analysis of reactions to stigmas. Journal of Personality and Social Psychology, 55, 738-748.

World Health Organization (WHO). (1997). Prevention and management of the global epidemic of obesity. In Report of the WHO, Consultation on Obesity, Geneva, June s.3-5. Geneva: WHO.

World Health Organization (WHO). (2013). Obesity and overweight (Online). Retrieved April 16th, 2016, from http.//www.Who. $\mathrm{int} /$ mediacentre/factsheets/fs311/en/ 